\title{
Experiências de escrita e escuta literária na cosmologia indígena com crianças em diferentes contextos culturais
}

Writing and literary listening experiences in indigenous cosmology with children from different cultural contexts

Marina Rodrigues Miranda Miranda

Maria Angélica Vago-Soares

\begin{abstract}
Resumo: Este texto trata de um estudo direcionado às culturas das cosmologias indígenas na referência de duas diferentes culturas de infâncias. A primeira constituída com crianças da etnia indígena Pataxó da Comunidade Indígena Pé do Monte - Monte Pascoal/BA. A segunda com crianças de um Centro Municipal de Educação Infantil, do município de Serra/ES. No verte da pesquisa com crianças Pataxó, o objetivo foi conhecer as suas cosmovisões ${ }^{1}$ nos conhecimentos de origens. A discussão teceu-se a partir de exercícios pedagógicos com uma literatura indígena de infância que foi produzida a partir do primeiro estudo. Nesta circularidade, este estudo analisa os dois campos de conhecimentos constituídos em exercício multifacetado, compondo a narrativa etnográfica destes processos. Os conhecimentos abordados das produções culturais constituíram uma pesquisa qualitativa com crianças, nas quais foram analisadas suas narrativas de conhecimentos cosmológicos na referência dos povos nativos, nos episódios interativos culturais, nas escolas de educação indígena e na educação formal. As discussões estão ancoradas nos estudos culturais de alguns autores indígenas e na sociologia da infância, que reconhece a criança como sujeito social ativo e provedores de culturas. O texto enfatiza o reconhecimento e a valorização das diferenças étnicas arroladas pelo contributo literário nos dois lócus de pesquisa. O que subjaz a discussão, é a desconstrução dos processos de opressões coloniais, tecendo estigmas de violação das populações indígenas que ainda permanecem no imaginário dos que pensam o mundo especificamente eurocentrado.

Palavras-chave: Cultura indígena. Educação escolar formal indígena. Infâncias.
\end{abstract}

Abstract: This text deals with a study aimed at indigenous cosmologies of cultures in reference to two different cultures since childhood. The first group was made up from the ethnicity of Pataxó indigenous children from the Pé do Monte Indigenous Community, Monte Pascoal, BA; the second one with children from a Municipal Child Education Center, in the municipality of Serra, ES. In the research with Pataxó children, the objective was to get to know their worldviews in the knowledge of origins. The other subject of discussion was woven from pedagogical exercises with an indigenous childhood literature that was produced from the first study. In this circularity, this study analyzes the two fields of knowledge constituted in a multifaceted

\footnotetext{
${ }^{1}$ As cosmovisões indígenas são diferentes maneiras das existências dos sujeitos ameríndios no que concerne as suas percepções, apreendências, transcendências e imanências das coisas do mundo em relação si e ao tempo-espaço de conhecimentos de mundo do outro diferente. Ressalto que esta cosmovisão se relaciona também aos seus próprios entes nas suas diferentes apropriações de mundo. Destaco que esta vista de mundo(s) não se resume somente a realidade concreta, configura-se as próprias cosmologias de conhecimentos apreendidas do mundo espiritual dos seus antepassados. (Miranda, 2021)
} 
exercise, composing the ethnographic narrative of these processes. The knowledge addressed in cultural productions constituted a qualitative research with children, in which their narratives of cosmological knowledge were analyzed in the reference of native peoples in the interactive cultural episodes in schools of indigenous education and formal education. The discussions are anchored in the cultural studies of some indigenous authors and in the sociology of childhood, which recognizes the child as an active social subject and providers of cultures. The text emphasizes the recognition and appreciation of the ethnic differences listed by the literary contribution in the two locus of research. What underlies the discussion is the deconstruction of the processes of colonial oppression, weaving stigma of violation of indigenous populations that still remain in the minds of those who think the world is specifically Eurocentric.

Keywords: Indigenous culture. Indigenous / formal school education. Childhood

\section{A pedra de toque}

Este artigo, em sua primeira parte, debruça-se à reflexão da Educação indígena das crianças da Aldeia Pataxó Pé do Monte, localizada na terra indígena Pataxó Barra Velha, no marco histórico de resistência dos povos indígenas do Brasil, uma aldeia com 48 famílias e 180 pessoas. A terra forte circunda os processos de produções culturais que atravessam os saberes de vidas dos seus moradores em sociabilidade identitária na tradição indígena, revelada no modo de produção da cultura Pataxó, em seus pressupostos da educação etnoecológica e etnoturística, e vinculados à principal identidade comunitária: o Monte Pascoal.

Os indígenas Pataxó conservam a mítica do Monte Pascoal como patrimônio de origem civilizatório, reafirmando-se nos conhecimentos ancestrais, como bainha de luta, como paredão de resistência dos povos originários do Brasil.

O Monte Pascoal, nosso Pé de Pedra, é terra indígena, baliza de nossa história, salão de nossas festas, altar e memória de nossos antepassados. Terra que representa o canto do paihó, sossego da onça pintada, o som do sabiá, o tinir da araponga, a sombra do jequitibá e tantas outras formas de vida da Mata Atlântica que queremos preservar, como sempre fizemos (POVO PATAXÓ, 2005)

Este marco ecológico remete à história de extermínio de algumas etnias, rememorando a saga de algumas aldeias que não usufruíam da mesma proteção e que foram dizimadas em prol da colonização. Nesse sentido, eles se mobilizam em defesa dos territórios herdados dos parentes, a fim de 
preservar a memória ancestral Pataxó e de outros povos indígenas, reconfigurando o patrimônio sociocultural, preservando o legado aldeado no Pé do Monte - Parque do Descobrimento - e partilhando o bem viver ${ }^{2}$ indígena na consciência de preservação planetária.

Como se observa, no enredo da cultura vibrante de preservação da vida cotidiana alicerçada nas ecologias de saberes, experienciadas por quem vive ao pé da pedra, torna-se contributo reflexivo à implicação do território refletido na educação indígena desta população seivada na valorização identitária.

Este pertencimento foi sentido e vivido no círculo de saberes na ocasião da primeira etapa da Conferência Nacional da Educação Escolar indígena (CONAEE), quando se referia ao coletivo de aldeados da Costa do Descobrimento refletia-se a composição ideológica das práticas pedagógicas realizadas nas escolas do território Pataxó, elencavam pressupostos educativos na dinâmica cultural. Almejava-se naquela conferência, avaliar os forjes etnocurriculares na "pedagogia do arco e da flecha" na legitimidade do currículo situado aos conhecimentos originários, analisado em seus sentidos epistemológicos e políticos. Importava saber se havia nos propósitos didáticos o arco curricular dos etnos-saberes, etno-formação (MACEDO, 2016). As lutas dos povos indígenas reafirmam e inspiram as bases etnocurrilares, conforme este autor menciona,

[...] qual a centralidade da composição teórico-conceitual de um etnocurrículo? De acordo com a perspectiva em que trabalhamos, trata-se da radicalidade do projeto etnometodológico que prega que, para todos os fins práticos, atores sociais não são "idiotas culturais", eles portam e criam etnométodos (GARFINKEL, 1967) acrescida de uma inflexão crítico-hermenêutica na qual esses atores, além de portar sentidos por meio das suas ações e realizações etnometódicas, são sujeitos criadores incessantes de sentidos

2 O bem viver é a forma de existência dos povos indígenas vinculada a memória ancestral dos seus antepassados, priorizando os seus modos de exitências e subsistências culturais vinculados aos ciclos da natureza e todos os seres que dela fazem parte. A cultura do bemviver é o contraponto à concepção capitalista de viver sobre a égide do consumo por forma resultar na exploração dos recursos naturais. O bem viver indígena tem como principio espiritual o respeito e sintonia com a terra-mãe. Esta visão coaduna com suas cosmologias (Miranda, 2021) 
e, com isso, por meio de suas ações, forjam e organizam suas ordens socioculturais, bem como teorizam sobre elas. Nesse veio, produzem descritibilidade, inteligibilidade, reflexividade, analisibilidades, lugar da emergência e das dinâmicas constituintes dos seus etnométodos (MACEDO, 2016, p. 11).

O princípio de conhecimentos nativos deste específico território baseiase na perspectiva cosmológica da comunalidade - atributo do que é a coletividade, na preservação dos processos histórico-culturais identitários, reverenciados na memória do lugar, Monte Pascoal - como marco de resistência ancestral. Na ocasião da conferência, o cacique Oziel Santana (como representante maior da aldeia) inspirado tomou a palavra com autoridade de mestre dos saberes da comunidade. Ele apresentou seus o atnométodos e refletindo os saberes da escola. Ele apresentou seus etnométodos, um viés político-pedagógico, encarnado à espiritualidade da memória ancestral, reafirmando os seus conhecimentos de origem, baseado no seu etnocurrículo ${ }^{3}$ e refletindo os saberes da escola, conforme mostra o trecho a seguir:

[...] sou pataxó, sou cacique da aldeia Pé do Monte. A minha casa e o meu quintal é como se fosse uma coisa só. Tenho liberdade de entrar e sair, de falar e de ouvir, de ensinar e de aprender. Neste território, o ensinamento e o aprendizado é nosso. Nosso é de todo mundo. No entanto, quando venho a para a escola, feito um dia como hoje, minha cabeça embola. Porque aqui, só em olhar eu vejo que o ensinamento já não é nosso. Se tivesse aqui todos os dias, o meu lugar de falar é depois que a aula termina. Não posso deixar de falar das coisas que acontecem no meu lugar, das histórias que ouvimos dos nossos pais quando querem ensinar a pescar, a jogar e lembrar das histórias dos nossos avós, de como eles viviam antes da aldeia ser Pé do Monte. [...] Como meu pai aprendeu a pescar um tambaqui, um beré, uma piaba, um caramuru? Quem fazia a peneira para usar na pesca? E a lança, quem ensinou a fazer? A fazer uma oca? A ouvir os passarinhos? A espantar galinha? A cortar mandioca e fazer beiju, farinha? A escola da vida indígena onde meu pai estudou ensinou tudo

\footnotetext{
3 Na referência dos estudos de Macedo(2012,p.6) etnocurrículo e etnoaprendizagem, bem como no detalhamento de seus fundamentos são configurados como currículo e aprendizagem por instituintes culturais. São constituídos pelos etnométodos dos atores sociais implicados. Isso permite compreender currículo e aprendizagem por meio do detalhamento de suas ações e suas processualidades situadas.
} 
isso pra ele? O que tem pra aprender na escola? ${ }^{4}$ (Cacique Oziel Santana, 2016)

Isto posto, concebemos que o Cacique reafirma o etnocurrículo para as escolas das aldeias. Cabe pontuar que a escola Pé do Monte é composta por um corpo docente de professora(e)s indígenas. Estes integram à escola os saberes da comunidade, como, por exemplo, a pauta escolar registra a identidade social Pataxó das crianças e, para além, registra o significado bilíngue - nas línguas portuguesa e patxôhã, valorizando-as em suas identidades.

Assim, não só reafirmam a ancestralidade Pataxó, como também conclamam a sustentabilidade planetária, nas etnoecologias nominativas: Yakanã Pataxó (protetor das matas), Jussari Pataxó (coqueiro alto), Tamikuã Pataxó (estrela), Jacian Pataxó (lua alta). São muitas estrelas, muitas luas, muitos coqueiros, protetores das matas, defensores de aldeia. Nessa mesma direção, Macena (2016) discorre sobre "o tempo da criança e da natureza na educação diferenciada guarani", posicionando-se frente à educação diferenciada para aldeias. Ele assinala que

[...] quando se trata da educação infantil, para nós tem muita importância, porque a educação, para o povo guarani, não é apenas uma formação. Formação, para nós, não é educação. Educação é onde há o respeito, uma cultura preservada, uma educação de forma tradicional. A educação onde você tem um grande conhecimento e sabedoria dentro da tradição. Essa é a educação do povo guarani. A educação não é uma caneta, um livro, uma escrita que faz você educado. Não adianta você ter a formação e você ser mal-educado. Então, isso também não serve nada. Para o povo guarani, educação é viver bem consigo mesmo. Então, isso que a criança aprende dentro da cultura guarani. A criança vai aprender, desde pequenininho, desde junto com a mãe, depois ela tem vários processos de conhecimento, de formação dentro da sua comunidade. A partir daí ela vai desenvolvendo (MACENA, 2016, p. 88).

É inegável que há um alinhamento da Educação Pataxó com a Educação Guarani, uma vez que ambas convergem quanto à necessidade de

4 Cacique Oziel Santana, durante a Oficina de Prática Pedagógicas Diferenciadas na Escola Pé do Monte - Monte Pascoal - CONAEE - Conferência Nacional de Educação Escolar Indígena. Primeira etapa: Comunidade Educativa na Escola da Aldeia é do Monte, Bahia, Brasil. 17/11/2016. 
edificar os vieses culturais, políticos e pedagógicos configurados as etnias experienciadas no chão de cada aldeia. E nesse processo de análise e construção de práticas pedagógicas, houve uma circularidade discursiva ao problematizarmos as questões que intervinham nos processos de aprendizagem das crianças. Nosso propósito foi ouvir cautelosamente os sujeitos da comunidade, evidenciados nas intervenções do cacique em defesa da permanência da educação escolar em seus processos pedagógicos para a preservação da tradição da cultura Pataxó para as crianças, legitimando-as a partir de suas territorialidades.

O desdobramento desse microcosmo aldeado emergente da resistência Pataxó é expresso nas relações de sociabilidade do grupo, consolidando práticas de conhecimentos na simbologia cultural do território. A preservação da memória cultural da aldeia paraleliza-se à identidade social e o diálogo do cacique confere e reafirma o currículo identitário para as escolas das aldeias. Nesses percursos, tecemos uma etnopesquisa implicada de observação e participação das ações na educação indígena no espaço escolar dessa comunidade, dialogando com as crianças em seus terreiros crenças e mitos, pensando o currículo de origem como direito cultural.

Neste terreiro de aprendizagem no sentido da vida nas refinadas estratégias das crianças indígenas, participamos ativamente da pluralidade da cultura, respeitada em seus etnosaberes. Depois de alguns encontros, brincando e convivendo, sugerimos o projeto "Pé da pedra - identidades Pataxó nas culturas de infâncias", tecido na linha de pesquisa Etnografia com Crianças, que observa conhecimentos de infâncias nesse campo de referência.

Discutimos todo o percurso do trabalho com estudantes de iniciação científica $^{5}$ em parceria com outra professora pesquisadora ${ }^{6}$ que participou de algumas sessões desta pesquisa. $\mathrm{O}$ trabalho de campo na escola gerou alguns desdobramentos, como a escrita de um livro. Essa escrita foi tecida

\footnotetext{
5 lanka Silva Rocha e Thais Nader Reis, ambas na ocasião, estudantes na Formação Geral do Colégio Universitário de Itamaraju, espaço universitário da Universidade Federal do Sul da Bahia.

${ }^{6}$ Karen Vieira, Professora de Serviço Social da UNB.
} 
inicialmente ao observarmos as crianças em seus tempos de aula e em suas vivências na aldeia, nos jogos pataxó e nos terreiros lúdicos das brincadeiras.

Nesse processo de observação e interação, compomos escritas e constituímos enredos literários para produção da história. No percurso, realizamos leituras de alguns fragmentos da composição criativa para crianças e professoras, percebendo o sentido da fruição das narrativas a fim de compor etnométodos que reverberassem processos de conhecimentos nativos.

No final da escrita, decidimos concluir a história em interação com as crianças e os professores para compor uma imbricação narrativa, pensando o currículo. Como elas já conheciam algumas tessituras de enredo, buscamos neste coletivo a inspiração para o desenlace da protagonista da história, uma menina indígena. Nossa intenção foi de aproximá-los da escrita viva, fazer leitura, brincar de ilustrar e propor interatividade narrativa na brincadeira do inventar.

Para envolvê-los na trama de modo descontraído, contamos a história em viva voz, com a finalidade de seduzi-los a adentrarem o mundo imaginado. No entanto, não seguimos a mesma estrutura do resumo que será exposto a seguir, por estarmos imersos no mundo da história no momento de contar, provocando sentidos ficcionais aos interlocutores.

Convém lembrar que contar e ouvir histórias são modos de sabedoria cultural do existir humano na apropriação do mundo em processos de socialização. Nesse contexto, no percurso de propor um enredo indígena, composto a partir dos sentimentos e pertencimentos culturais das crianças da aldeia, fundamentaram-se alguns ricos arremedos linguísticos celebrados entre os contadores, elos que contribuíram para a imersão identitária com o grupo social estudado.

Partindo dessa proposição, para que os leitores deste texto adentrem o tempo-narrativo das crianças, apresentamos resumidamente a história "Aranã e a cacimba" (MIRANDA, 2018).

Esta é história mágica, conta a história de Aranã, uma menina indígena muito valente, que morava na Aldeia Velha, a aldeia velha a mais antiga do lugar, por isto é a aldeia mãe. A aldeia é cercada de muito verde da Mata Atlântica. A menina era 
atrapalhada, "amolada" adorava brincar, gostava de mandar em toda brincadeira. Ela tinha medo de alguns bichos da mata, principalmente sapo.

- Sapo nem para olhar, quanto mais para brincar (dizia Aranã).

Este era realmente seu maior medo.

Até que um dia ela estava brincando: - dorme, dorme, dormideira para acordar segunda-feira.

Não sei o que aconteceu, escureceu tudo, ficou um breu e aldeia desapareceu.

Aranã pensava: - Será que foi feitiçaria?

Era tudo escuridão e para piorar, Aranã tropeça e cai no fundo do poço. Só que na parede do poço tinha um grande galho, de alguma árvore subterrânea, Aranã ficou presa no galho.

Aranã pensava que estava sonhando, sonhou que estava deitada em plantação de abóbora, mas no fundo, no fundo. Estava no fundo do poço, com um sapo gigante - O Aru. Na escuridão, Aranã deu de cara com olho esbugalhado do sapo, tão grande que era maior que sapo-boi.

O coração de Aranã batia forte, muito forte. Ela começou a chorar e o sapo, não gostou.

Ela não sabia se chorava ou se ficava amiga do sapo. Queria mesmo que ele a ajudasse a sair daquele grande poço. E lá fora, será que a aldeia apareceu? De dentro do poço nada se via.

Depois de muito chorar, adivinham o que aconteceu?

Defendemos que instigar as crianças a contarem histórias no movimento, as levam a acessar tessituras simbólicas dos mundos imaginados das infâncias, e emergem constituições de autorias. Segundo Bakhtin (2015), o conceito que nos apropriamos para tratar da narração de histórias é o de "relação dialógica" da linguagem.

Sob essa perspectiva, a criança ao contar uma história, interage e se apropria da palavra do outro, por meio do processo de interação que ocorre entre o contador e o ouvinte. A partir desse entendimento, refletimos que mesmo antes de a palavra ser proferida, esta já pertence ou foi influenciada pelo outro, tratando-se de questões exteriores à própria língua. Como as crianças são perpassadas por "culturas", nesse mecanismo de criação provocam-se autorias ativas na arte de inventar, arte que culminou não 
somente na criação de um novo fim para a história que estava sendo contada, mas também na ilustração de enredos possíveis. Nesse movimento, todas (os) queriam se arriscar a idealizar o fim, desenhando, oralizando, oralizandodesenhando. Percebemos que essa euforia emergente da busca pelo fim provocou uma história sem fim.

Com efeito, o que se almeja é analisar as narrativas das crianças, somadas aos textos escritos e imagéticos. O significado de narrativa, sob a ótica de Stephens (1992), perpassa a composição imbricada por componentes: i) A história - composta por personagens envolvidos nos acontecimentos, num espaço e tempo determinado, viabilizando o processo de análise do que se é contado; ii) $O$ discurso - que tem como premissa especificar a forma de apresentação da história; iii) A significação - que demanda conhecimento do contexto para o que o ouvinte-leitor-expectador possa interpretar o entrelaço da história e o respectivo discurso em razão desta.

Atentemos agora, as imagens que seguem:

Figura 1 - O sapo pesado e o chão

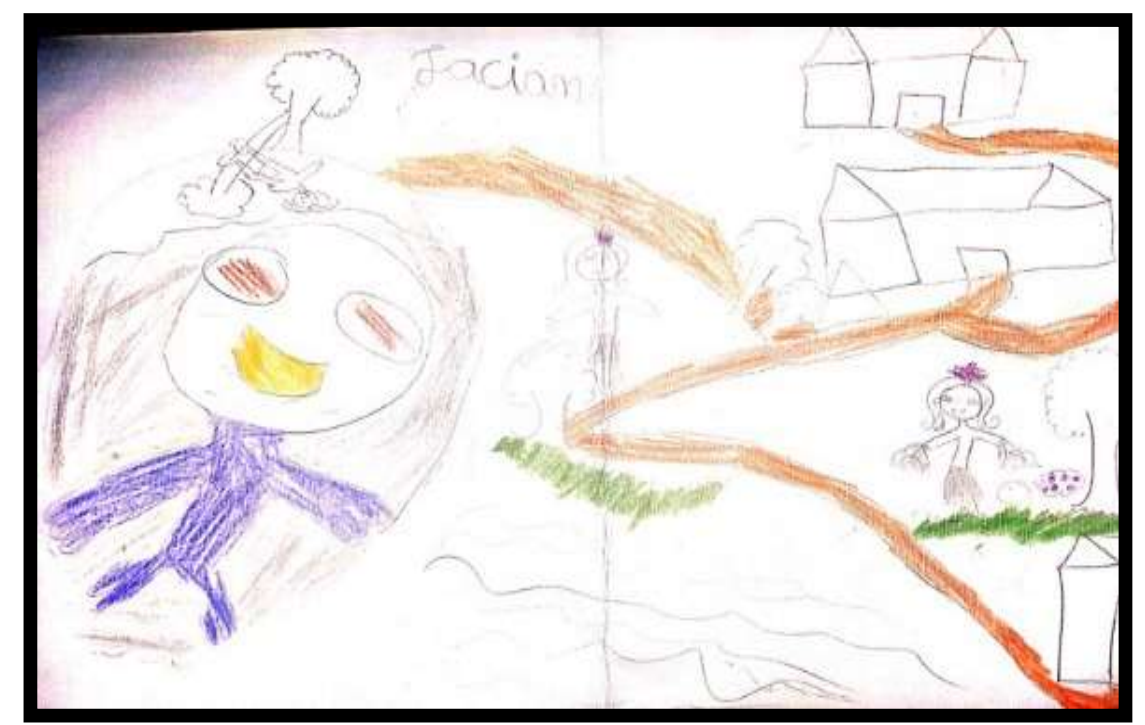

Fonte: acervo da pesquisadora

Jacian em seu processo de criação fez a leitura da própria produção: "O sapo era muito pesado e o chão começou a abaixar...". Ao observar a narrativa e a ilustração referente a história (Aranã e a cacimba), Jacian Pataxó (6 anos de idade), no seu desenho há algumas representações de curvas de nível que 
mostram nitidamente a irregularidade do terreno (onde Jacian reside - Monte Pascal). Mostra também o sapo gigante em um chão movediço que começa a descer, com o tremor da terra tudo perde equilíbrio. O terreno torna-se irregular, acidentado, pelo enorme peso do sapo. Para além dessa leitura, a identidade cultural é o contraponto, por apresentar elementos pertencentes à aldeia, a exemplo, a representação que Jacian faz do seu território (espaço físico), pois essa aldeia situa-se no pé de um monte - Monte Pascoal.

Já Tamikuã (8 anos) em sua ilustração (fig. 2) contrapõe a história que foi apresentada para a realização da atividade. Nessa discordância, muda-se o rumo da história: "Na hora que o sapo chegou perto de Aranã, ela fechou os olhos e beijou o sapo, ao invés dele virar príncipe, Aranã que virou sapinha". A menina, Tamikuã, subverte a ordem dos contos de fada, nesse caso o protagonismo é dado a personagem feminina.

Figura 2 - O sapo chega perto de Aranã

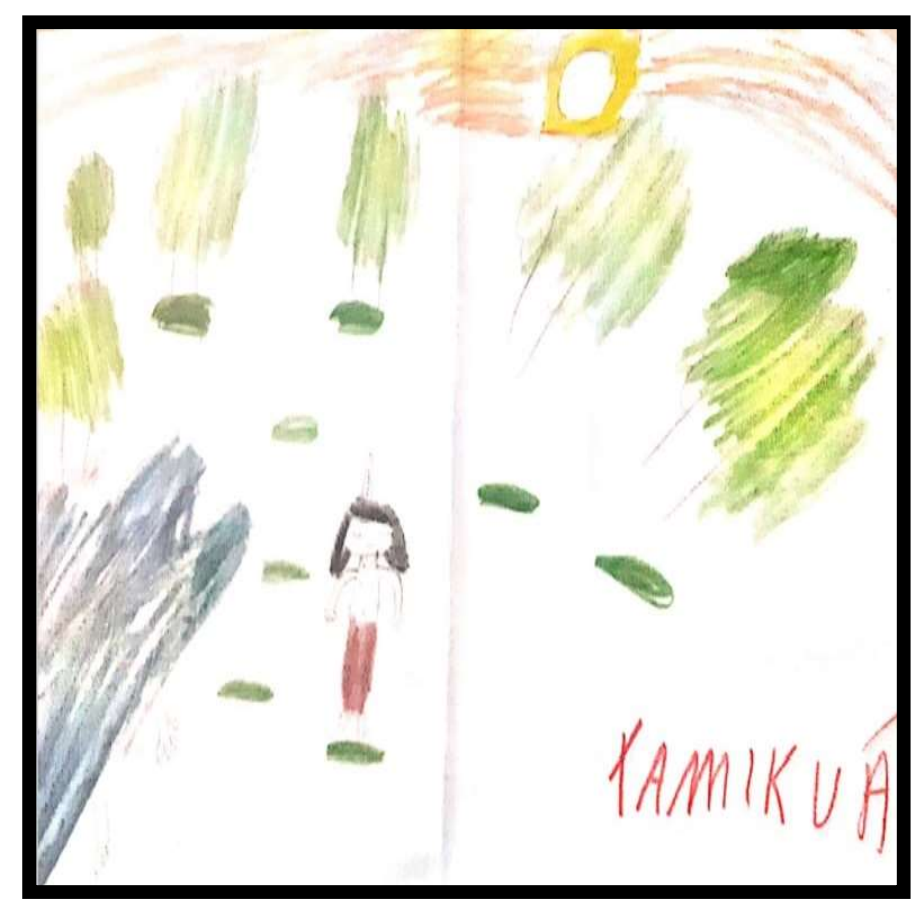

Fonte: acervo da pesquisadora

A proposição ilustrativa atrelada à narrativa, ressalta o poder da mulher na aldeia. A ideia de o sapo virar príncipe não se sustenta na cultura indígena pela condição da circularidade da energia cosmológica, o homem e a mulher no universo indígena Pataxó, desenvolvem funções diferenciadas em que os 
papéis sociais são valorizados em ambos. Assim, o sapo gigante transformouse em um bichinho indefeso e aprisionado. Aranã perdeu o medo, saiu do poço, empoderou-se como a guardiã da aldeia.

A historicidade projetada torna-se refazimento da vida, atrelando enfrentamento - resistência do povo Pataxó. Valer ressaltar que as crianças participaram do processo de escrita, em pequenos trechos no tempo de construção da história, portanto, as unidades discursivas foram tecidas em paralelo com a obra em si, corroborando para essas possíveis interpretações.

$\mathrm{Na}$ ocasião dessas produções, Suruí Pataxó, um pequeno menino de cinco anos, estava no colo do pai, este enquanto rabiscava o desenho (fig. 3). No meio do processo criativo, ele teceu um fio de conversa: "Achei que o sapo fosse virar morador da aldeia, ficar entre o poço e a aldeia" - nesse depoimento, ressalta-se a liberdade de ir e vir do homem na aldeia. Na pausa, a criança tomou a rédea do discurso: "Por que ela não toma coragem e fica amiga do sapo? - Aqui tem monte de sapo, né pai!? Eu também tenho coragem!" No interdiscurso, nasceu ali um guerreiro.

Figura 3 - Caxiló Pataxó

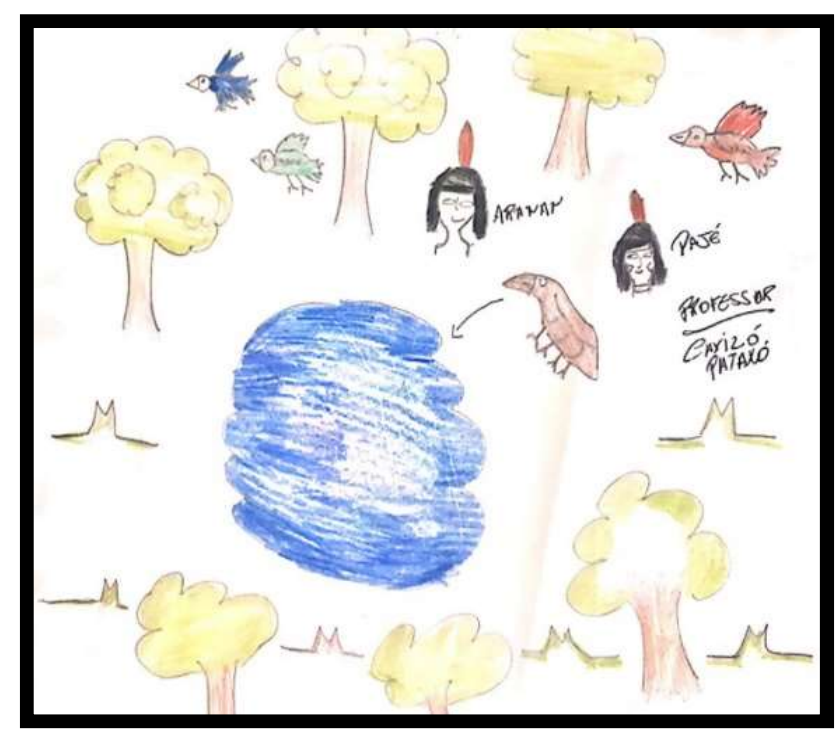

Fonte: acervo da pesquisadora

Nas comunidades indígenas, as crianças vivem em sintonia com a natureza e são livres na aldeia; sempre estão acompanhadas de outras crianças. Na aldeia Pé do Monte, é costumeiro os pais irem à escola com os 
filhos, e permanecem na sala por um determinado tempo, chegando a debruçassem na janela, até retornarem para suas casas. Nesse episódio interativo, percebemos a simbiose entre pai/filho e professor/aluno, ambos aprendizes da natureza indígena, que não forjam o tempo em prol de nada; por viver em comunhão com a natureza, vivem na mesma cronologia, da lua, das marés, das estações.

Nesse espaço de ação colaborativa, o silêncio se prolongou, pois estavam todos concentrados no tempo de criação. Após refletir sobre a ilustração realizada pelo professor Caxiló e Suruí estavam em sintonia com a história, criavam um repertório propício para trocas de aprendizagens entre paifilho, compartilhamento de ecologias de saberes criança-adulto na cultura que partilha o mundo do bem viver, em sintonia com a natureza.

Essa ilustração (fig. 3) merece relevo, pois o esmero da produção está nos elementos da natureza, nos pássaros de diferentes espécies, num mundo sustentável em meio a muito verde, representando a Mata Atlântica e a diversidade de aves que lá habitam. Para finalizar a produção, identifica-se profissionalmente como professor e imprime uma assinatura, legitimando-se a autoria da obra de arte.

Aprendemos nesse extrato de tempo, durante quase quatro anos exercitando o tempo de aldeia, que a vida bem vivida perpassa pela valorização de todos os "parentes", distantes e próximos. Os povos indígenas constituem uma grande comunidade, à guisa de conclusão das histórias inventadas elas se dimensionam na tessitura, na composição.

Sendo a produção ato comunitário, vejamos a seguir "o fim" tramado na invenção imaginada das pesquisadoras (estudantes e professora colaboradora) e da professora indígena.

"Como a indiazinha tinha muito medo do sapo, o sapo falou para ela que não precisava ter medo, resolveu fazer uma brincadeira com ela, vou te mostrar como é ser sapo e ele espirrou aquele leite nela e a indiazinha virou sapo". (Karen Vieira, professora) 
Figura 4 - A cacimba (Karen Vieira)

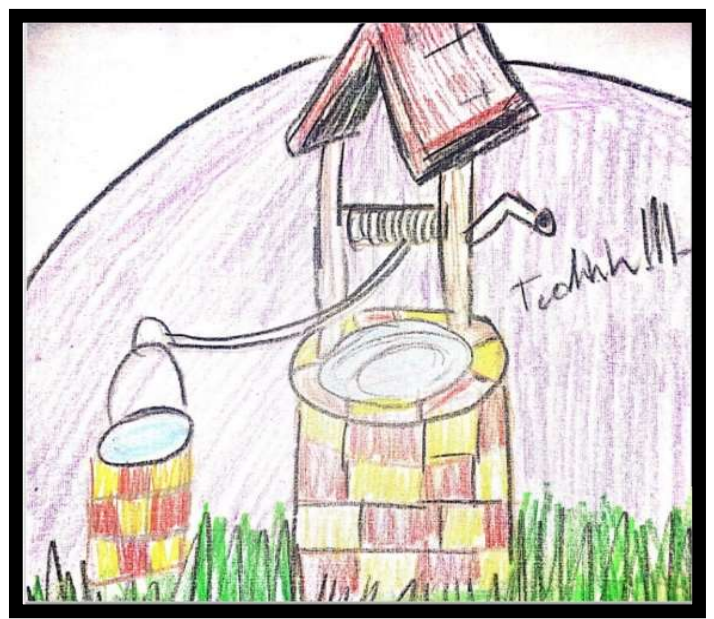

Fonte: acervo da pesquisadora

"Apareceu o pajé, ele pegou uma poção mágica, jogou no poço e transformou todo mundo em amiguinho e ficaram morando lá. Depois, o pajé voltou no poço e fez Aranã voltar ao normal. Aranã e o sapo passam a brincar dentro do poço. Que virou uma passagem secreta deles". (lanka Rocha, estudante).

"O sapo, na verdade, era um grande guerreiro da aldeia, voltou ao normal e se apaixonou pela indiazinha." (Roseni, professora indígena)

Figura 5 - O Aru: o sapo gigante (Karen Vieira)

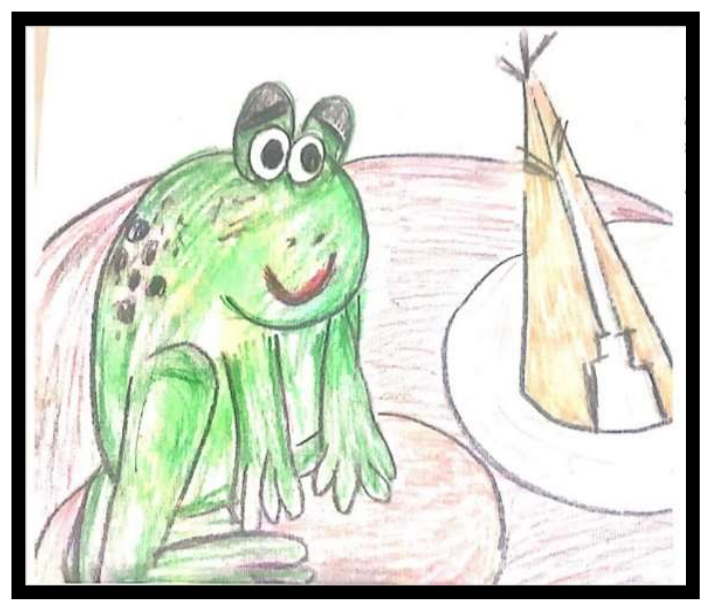

Fonte: acervo da pesquisadora 
Comentando sobre essa busca pela estruturação de um possível fim, Calil (2009) afirma:

"Fim" em seu estatuto de unidade de sentido, surge invariavelmente, no final da maioria das histórias escritas por alunos. [...] Esse efeito, parece estar relacionado a outros "textos", em que tal palavra surge como, por exemplo, os gibis e certos filmes. Neste lugar o sentido de "fim" está congelado, tem sentido cristalizado, que funciona como se fosse único. A palavra fim não é nova, nem diferente, mas, ao descongelar, muda de lugar, rompendo com uma suposta "estrutura". (CALIL, 2009, p. 105)

Como as crianças são provedoras de culturas, nesse mecanismo de criação, provocam-se autorias ativas na arte de inventar das crianças, que culminou não somente em reinventarem a história, mas ainda na ilustração de seus enredos em diferentes processos imaginados. Percebemos na produção que as crianças indígenas configuraram narrativas, que aportam as vivências cotidianas da aldeia, e que aquilo que havia de pânico na relação sapo-menina indígena, se dissipa entre as crianças da aldeia, que vivem com sapo harmonicamente, e o antagonismo desaparece.

Para além, as representações sociais de gênero na aldeia são demarcadas: a relação homem-mulher é mais horizontalizada que na sociedade não indígena. Esses etno-saberes da comunidade também foram representados nas curvas de níveis dos desenhos; a aldeia é sempre apresentada a partir do alto do monte, sinalizando que monte é sagrado, celeiro de afirmação étnica Pataxó.

Destarte, compete a nós, educadores, reverberar o universo narrativo pataxó, possibilitando outras infâncias a refletirem no campo de suas culturas, outras cosmologias ${ }^{7}$ de conhecimento, no caso as culturas de infâncias indígenas Pataxó. E com isso, consolidar as crianças que não conhecem a realidade das aldeias, por morarem na cidade. Esse é um convite para o conhecimento da educação indígena pelo viés da cultura, do patrimônio humano, que agregam valores culturais milenares e herança de antepassados,

\footnotetext{
7 A cosmologias estudam o universo de uma dada cultural em seus saberes contituidos. No caso dos povos indígenas são experiências, saberes e tradições originárias destas populações na especificidade da cultura de cada povo.(Miranda, 2021)
} 
pelo conhecimento das identidades de crianças indígenas por outras crianças. Partimos para a cidade de Serra/ES, rumo a uma outra prática educativa de infância, produzida de modo criativo, lúdico e com perspectiva educativa ambiental solidária.

Nesse trajeto como pesquisadoras de infâncias, fomos desafiadas a propor um trabalho de mesma base literária, buscando contrastar o exercício de plenitude de conhecimentos das crianças cidadãs na composição com o contributo literário indígena. Para isso, empreendemos princípios respeitosos às feituras de crianças em suas tramas imaginadas: i) princípio do respeito ao direito do brincar, garantido no estatuto da criança e do adolescente; ii) princípio da ética em pesquisa com criança, respeitando os seus propósitos de brincadeiras sem invadir seus espaços; iii) princípio da responsabilidade de promover as práticas educativas para educação de infâncias alicerçadas à educação para a diversidade.

No exposto, a composição do texto abrange discussões do campo da sociologia da infância e de outras teorias, como antropologia da criança que fundamentam o trabalho neste campo. A produção lúdica literária ocorreu na perspectiva do ensino de Arte, por assim se compor e adentrar ao campo da Educação Formal. Nesse viés, o mote de escrita toma outros sentidos, outros significados, na partilha desde tempo de trabalho.

\section{Narrativas com a arte e culturas indígenas}

As experiências produzidas com crianças da educação infantil foram desenvolvidas a partir de conversas sobre a diversidade artística e cultural, que se estabeleceram a partir de um projeto de ensino, no final do ano de 2018, em momento de docência em Arte, com crianças do Centro Municipal de Educação Infantil (CMEI) - Professora Maria Hilda Aleixo, localizado no bairro Carapina Grande no município da Serra/ES. O projeto teve como dispositivo didático a obra literária Aranã e a cacimba (MIRANDA, 2018), vale ressaltar que esses alunos já haviam tido um contato com essa história, a qual foi trabalhada em diferentes sequências didáticas. 
Entendemos a importância de se desenvolver práticas educativas nas aulas de arte para crianças de forma lúdica com a mediação da literatura infantil, e que incluam abordagens diversas, tendo em vista as diferentes manifestações artísticas e culturais. Isso porque os livros

[...] são mediadores que despertam imagens mentais, viagens fantásticas pelo mundo imaginário. $O$ prazer de ler, do contato amoroso e tátil com os livros é mediado primeiramente pelo outro, também leitor sensível. Depois, já fisgado pela leitura, ampliamos nossa possibilidade de ler para além das imagens e letras (MARTINS; PICOSQUE, 2012, p. 29).

Assim, como mediadores de conhecimentos, os livros compartilham histórias que nos movem em busca da concretização de sonhos, possibilitando novos olhares, respeito e inclusão de narrativas diversas. Benjamim (2007), em relação ao poder de mediação da literatura, defende que os livros

[...] servem para introduzir os seus leitores, de maneira imediata, no mundo dos objetos, animais e seres humanos, para introduzi-los na chamada vida. Só aos poucos o seu sentido vai se constituindo no exterior, e isso apenas na medida em que se estabelece uma correspondência adequada com seu interior. A interioridade dessa contemplação reside na cor, e em seu meio desenrola-se a vida sonhadora que as coisas levam no espírito das crianças. Elas aprendem no colorido [...]. (BENJAMIN, 2007, p. 62)

A criança aprende e se diverte com os personagens das histórias, com os cenários e adereços que envolvem todo o contexto narrativo. A contemplação aguça os sentidos expressos na corporeidade, interagindo com a história, imbricando uma passagem imaginária para outros espaços-tempos, sugeridos pela narrativa e imaginados por cada criança no desenrolar dos acontecimentos. É fato que "na vida há momentos de diferentes experimentações que aguçam de forma tão potente os sentidos, que ficam impressos em nossas memórias por muito tempo e até por toda a vida. Essas experiências contribuem com a formação humana" (VAGO-SOARES, 2015, p. 44).

A ludicidade desencadeada pela história Aranã e a cacimba possibilitou a construção de conhecimentos sobre a arte e as culturas indígenas. A história foi mediadora da produção de conhecimento e da recriação. Entendemos que 
"mediar [...] é propiciar espaços de recriação da obra [...]" (MARTINS; PICOSQUE, 2012, p. 18), e a criança constrói seus conhecimentos fazendo relações entre os que já possui e aqueles que lhe foram apresentados, recriando-os, reelaborando-os, produzindo outros conhecimentos. De acordo com Kramer,

[...] a história é compreendida não como linear ou mecânica, mas como entrecruzamento de presente-passado-futuro; a história é entendida como narrativa [...] a partir da leitura de sua obra que o homem se faz fazendo o mundo, e se faz como homem se fazendo na linguagem, processo que só é possível graças à coletividade, ao nós [...] (KRAMER, 1998, p. 214).

Os repertórios imagéticos/discursivos se ampliam e se constituem na coletividade, como modo de valorização de si e dos outros, de sua comunidade. Nessa orientação, o planejamento para a educação infantil deve levar em consideração os eixos do currículo, interações e brincadeiras, propostos nas Diretrizes Curriculares Nacionais para a Educação Infantil. Esse documento enumera doze experiências que precisam ser garantidas para as crianças, entre elas, a de propiciar "a interação e o conhecimento pelas crianças das manifestações e tradições culturais brasileiras" (DCNEI, 2010). Isso posto, ressaltamos a importância de desenvolver práticas que incluam experiências com diferentes manifestações culturais como meio de potencializar o reconhecimento dos sujeitos em seus pertencimentos,

[...] pois qual o valor de todo nosso patrimônio cultural, se a experiência não mais o vincula a nós? A horrível mixórdia de estilos e visões de mundo do século passado [século XIX] mostrou-nos com tanta clareza onde esses valores culturais podem nos conduzir quando a experiência nos é subtraída, hipócrita ou sorrateiramente, que é hoje em dia uma prova de honradez confessar nossa pobreza: essa pobreza não é apenas pobreza em experiências privadas, mas em experiências da humanidade em geral (BENJAMIN, 2012, p. 124-125).

Nesse sentido, a experiência torna-se necessária para nossa formação, tendo em vista não apenas o individual, mas também o coletivo. É fato que essas experiências não devem ser incluídas no currículo somente em momentos de datas comemorativas, como praticado por muitos professores, por exemplo, quando elegem dias dedicados ao índio ou à consciência negra 
para planejar ou mesmo improvisar uma atividade relacionada a esses temas. Segundo Brandão (2009), o acontecer da cultura está tanto em seus produtos materializados (construções, artefatos, ferramentas, entre outros), quanto nos imaterializados, é

"[...] na tessitura de sensações, saberes, sentidos, significados, sensibilidades e sociabilidades com que as pessoas e grupos de pessoas atribuem socialmente palavras, ideias, visões e versões partilhadas ao que vivem, criam e fazem que as culturas se manifestam e fazem parte de nosso cotidiano (BRANDÃO, 2009, p. 716).

Feitas essas premissas, o objetivo geral do projeto pedagógico na escola do município da Serra, foi instigar os sentidos das crianças para as imagens das brincadeiras das infâncias indígenas e, de maneira lúdica, possibilitar a partilha de experiências com a arte e a cultura, tendo em vista a reelaboração destas.

Como embasamento teórico-metodológico, compreendemos que o ensino da arte com as crianças necessita da percepção dos professores quanto à diversidade, como meio de inclusão e valorização das diferentes manifestações artísticas e culturais. A criança expressa aquilo que vê e sente. Por isso, a arte e o ensino devem estabelecer conexões culturais, articulando a cognição, a imaginação, a apreciação e a produção (BARBOSA, 2009).

O projeto de ensino teve sua construção em momento de conversa sobre diferenças, implicando a inclusão da cultura indígena no currículo. A dinâmica foi mediada a partir de produção de autorretrato, em uma aula anterior. A partir das diferenças percebidas, do olhar-se no espelho e desenhar-se, as crianças foram se reconhecendo.

Segundo Kramer (1998, p. 222), temos "[...] dificuldade de aceitar as diferenças e de reconhecer que aquilo que caracteriza nossa singularidade é justamente nossa pluralidade [...]", pois somos seres envolvidos por culturas. Nas percepções das diferenças identitárias postas na produção de conhecimento de si, foram construídas relações de pertencimento e alteridade, do outro que é diferente, mas que se reconhece na cultura indígena, pois uma das crianças do $\mathrm{CMEI}$, disse ser parecida com um índio. 
Nesse momento, se deu a escolha do livro "Aranã e a cacimba", com o intuito de mediar as conversas e práticas artísticas e culturais desse contexto. As experiências com a arte e a cultura indígena foram muitas. A história foi contada com a participação de palitoches (fantoches produzidos com palitos de picolés, papel cartão, tintas e outros materiais) inspirados pela literatura indígena referendada. Desse início, dimensionamos outras ações, das quais compartilhamos algumas.

Uma delas é que a narrativa foi recontada pelas crianças. É relevante ponderar que a história está sempre em processo de acabamento, em processo de transformação. Cada história é o ensejo para uma nova narrativa, que desencadeia outra e outra. A memória é ilimitada, bem como o imaginário, ambos estão em constante refazer-se (BENJAMIN, 2012). Seguindo essa ação, as crianças puderam brincar de pique-esconde utilizando os fantoches como personagens da brincadeira, reelaborando fragmentos da história (onde Aranã brinca com os bichinhos da floresta). Assim, a criança

[...] utiliza sua imaginação para aquilo que acha conveniente no instante do seu brincar, deixando fruir a fantasia, produzindo seus próprios discursos, estabelecendo relações entre o real e o imaginário, mesmo tendo consciência de que está fantasiando no momento em que brinca. Em seus brincares, torna-se personagens de contos de fada, de desenhos animados [...] (VAGO-SOARES, 2015, p. 47).

Nos brincares se aprende e se ensina, entre adultos e crianças, entre crianças e crianças. Foram realizadas as atividades didáticas citadas e em seguida, marcamos um encontro na escola com a autora do livro para que as crianças pudessem conhecer o universo da composição da obra. Juntos, experienciamos momentos lúdicos em diálogos com a arte das culturas indígenas.

As crianças também confeccionaram cocares e colares. Os cocares foram produzidos com papéis, utilizando técnica de recorte e colagem, já os colares foram confeccionados a partir da pintura de macarrão e da composição deles em barbante. $O$ processo de produção dos brinquedos se deu na interação e na brincadeira, como se pudessem experienciar fragmentos da história. Essa produção por elas nos importa porque, "[...] quanto mais 
atraentes, no sentido corrente, são os brinquedos, mais se distanciam dos instrumentos de brincar; quanto mais ilimitadamente a imitação se manifesta neles, tanto mais se desviam da brincadeira viva [...]" (BENJAMIN, 2007, p. 93).

As crianças ao se enfeitarem como a personagem Aranã, em sua maioria, quiseram olhar-se no espelho para apreciarem suas imagens com os adornos e, mesmo levando para casa, em dias posteriores, ainda se enfeitavam com suas produções: "[...] o que acontece nas aulas de arte de uma instituição escolar é muito mais resultado de um conjunto de fatores sociais e culturais do que apenas de aspectos gerais, que não contemplam um ensino interativo e dinâmico [...]" (VAGO-SOARES, 2015, p. 17).

Nas figuras (6) e (7) o desenho e a pintura com tinta guache foram alguns dos modos de expressividade infantil, no decorrer do projeto. Cada criança expressou de modo singular aquilo que considerou mais relevante na história.

Figura 6 - desenho e pintura com tinta guache

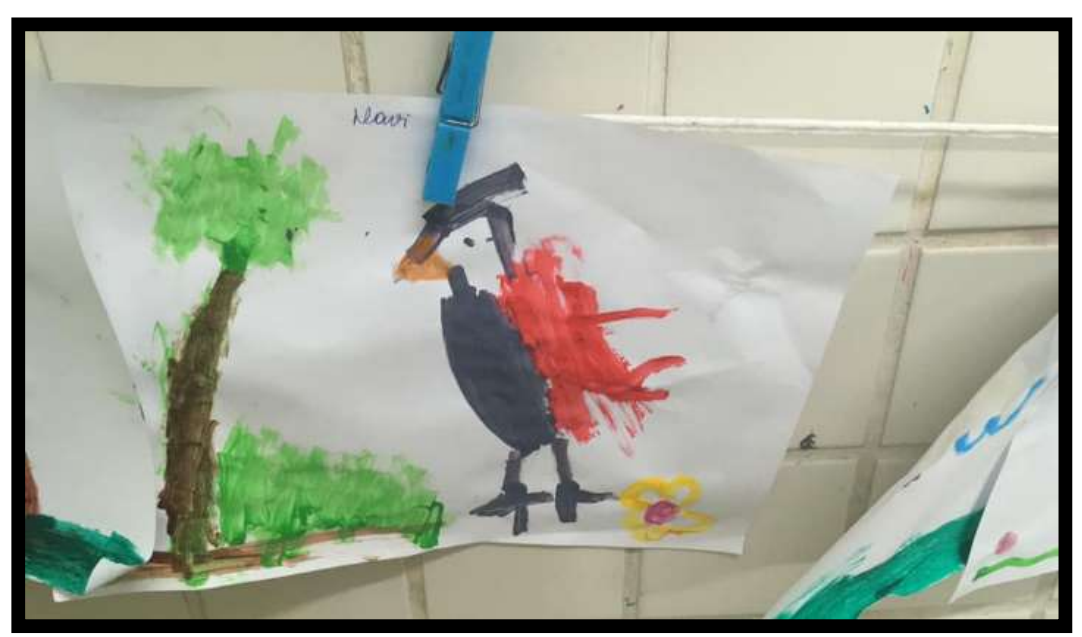

Fonte: acervo da pesquisadora

As experiências possibilitaram a ampliação do repertório artístico, cultural e identitário das crianças, além da apropriação de modos de ver e falar sobre as imagens. Também possibilitou a elas a produção de conhecimentos sobre a importância e a valorização das culturas infantis, em especial, as indígenas. 
Figura 7 - desenho e pintura com tinta guache

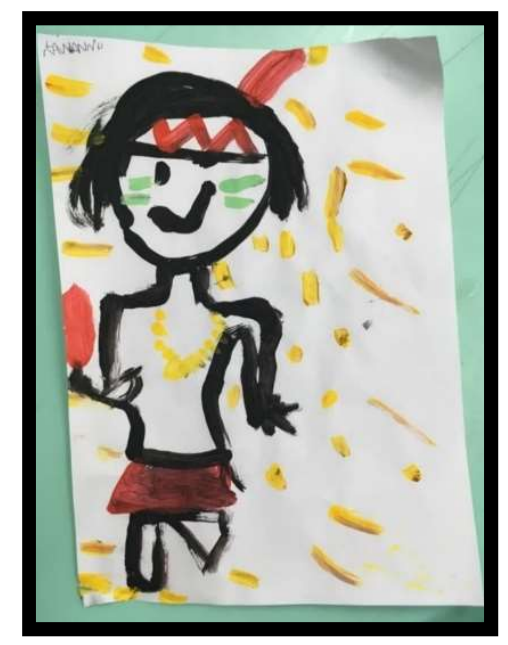

Fonte: acervo da pesquisadora

No exposto, as crianças em seus patrimônios do brincar, vivenciaram o lúdico nos diversos modos da cultura pataxó, empenhadas na relação de alteridade com o imaginado dessas infâncias indígenas.

[...] a experiência cultural para a formação de crianças, jovens e adultos, [...] enraíza, resgata trajetórias e relatos, provoca a discussão de valores, crenças e reflexão crítica da cultura que produzimos e que nos produz, suscita o repensar do sentido da vida, dos valores da sociedade contemporânea e, nela, do papel de cada um de nós [...] (KRAMER, 1998, p. 217).

O propósito de entrecruzar o projeto Pé da pedra - identidades Pataxó nas culturas de infâncias, na escola da Aldeia Pé do Monte, com o projeto Brincares com a Aranã e a Cacimba - foi almejado, sobretudo, no pilar da nossa proposta de incluir e de aprender o bem viver planetário, inspirado nos modos dos povos originários. $E$, para que a inspiração se concretizasse, a premissa foi encorpada à valorização pluriétnica da vida, encorpamos este mote e o partilhamos no exercício do bem viver aos modos indígenas: 
[...] O pilar do bem viver é reconhecer-se como parte de uma grande comunidade de sujeitos humanos relacionados entre si e com tudo mais, num mundo interdependente. A condição do bem viver é saber relacionar-se, é sentir-se parte de tudo e de todos, é usufruir a vida que decorre das relações de troca e dependência com o entorno. [...] Aí entram como sujeitos tanto os humanos como todos os elementos da natureza (o ar, a chuva, a água, o Sol, a Lua, as montanhas, os animais, as plantas...), bem como os mortos e os espíritos. As relações entre estes conjuntos de sujeitos são de respeito e troca, tendo como pressuposto incontornável a dependência mútua (MACENA, 2016, p. ???).

Assim, consideramos que os propósitos educativos de infâncias foram alcançados em diferentes tempos e contextos de culturas. Vitalizamos encarnadamente a cultura indígena no corpo vivido, percebido e representado nos jogos cooperativos com as crianças em suas específicas infâncias, respeitando as diferenças entre si. Cremos ter proporcionado ludicamente um tempo do bem viver indígena, sendo considerado um possível caminho para o acolhimento respeitado nas cosmologias plurais.

\section{Referências}

BAKHTIN, Mikhail Mikhailovich. Estética da criação verbal. 5. ed. Tradução P. Bezerra. São Paulo. Martins Fontes. 2010.

BARBOSA, Ana Mae. Mediação cultural é social. In: BARBOSA, Ana Mae; COUTINHO, Rejane Galvão [Orgs.]. Arte/educação com mediação cultural e social. $2^{a}$ reimp. São Paulo: Editora UNESP, 2009, p.13-22.

Paulo: Cortez, 2015.

Redesenhando o desenho: educadores, política e história. São

BENJAMIN, Walter. Reflexões sobre a criança, o brinquedo e a educação, 34. ed. São Paulo: Duas Cidades, 2007.

Magia e técnica, arte e política: ensaios sobre a literatura e história da cultura. 8 ed. São Paulo: Brasiliense, 2012.

BRANDÃO, Carlos Rodrigues. Vocação de criar: Anotações sobre a cultura e a cultura popular. Cadernos de Pesquisa. São Paulo, v. 39, n.138, p. 715-746, dez/2009. Disponível em: http://www.scielo.br/pdf/cp/v39n138/v39n138a03.pdf acesso em: 4 de maio 2019.

BRASIL. Ministério da Educação. Diretrizes Curriculares Nacionais para a Educação Infantil. Brasília, 2010. 
CALIL, Eduardo. Autoria: A criança e a escrita de histórias inventadas. 2.ed, Londrina, Eduel, 2009.

KRAMER, Sonia. O que é básico na escola básica? Contribuições para o debate sobre o papel da escola na vida social e na cultura. In: KRAMER, S.; LEITE, IM. I. (Orgs). Infância e produção cultural. 5 ed. Campinas/SP: Papirus, 1998. Cap. 1, p. 11-24.

MACEDO, Roberto Sidnei... [et tal]; Currículos e processos formativos: experiências, saberes e culturas. Participação de Pierre Dominicé; Salvador: EDUFBA, 2012.

MACEDO, Roberto Sidnei. Instituintes culturais de experiências formativas: bases para um etnocurrículo. In: Alves, Rita de Cassia Dias Pereira; NASCIMENTO, Claudio Orlando Costa (Orgs). Formação Cultural: sentido epistemológico e político. Cruz das Almas, EDUFRB, Belo Horizonte, Fino Traço, 2016.

MACENA, Pedro Luiz. O tempo da criança e da natureza na educação diferenciada guarani. In: Conselho Regional de Psicologia de São Paulo. Povos indígenas e psicologia: a procura do bem viver. São Paulo: CRP/SP, 2016. cap.10, p. 83-88.

MARTINS, Mirian Celeste; PICOSQUE, Gisa Mediação cultural para professores andarilhos da cultura. São Paulo: Intermeios, 2012.

MIRANDA, Marina R. Aranã e Cacimba, Vitória-ES, Edição da autora, 2018.

MIRANDA, Marina. R...[et all] Guardiões e Guardiãs da terra e do céu; cartas originárias de crianças indígenas para o mundo. São Paulo: Tupiaba Projetos Originários; 2021.

MIRANDA, Marina. R...[et all] Guardiões e Guardiãs da terra e do céu; cartas originárias de crianças indígenas para o mundo. Campo de Goytacazes (RJ): Encontrografia, 2020.

POVO PATAXÓ. Leituras Pataxó: raízes e vivências do povo pataxó nas escolas/ Secretaria de Educação. Salvador: MEC/ FNDE/ SEC/ SUDEB, 2005.

STEPHENS, Jonh. Language and ideology in childrens literature. New York: Longman publishing, 1992.

VAGO-SOARES, Maria Angélica. Infância, arte e cultura: experiências em (com)textos educativos. ed. São Carlos, SP: Pedro \& João Editores, 2015. 


\section{Sobre os Autores}

\section{Marina Rodrigues Miranda Miranda}

marina.miranda@ufsb.edu.br

Professora Especialista em Orientação Acadêmica em EAD pela Universidade Federal do Mato Grosso (UFMT); Especialista em Educação Física Escolar pela Universidade Federal do Espirito Santo (UFES); Mestra em Educação pela Universidade Federal do Espírito Santo (UFES/2007) e Doutora em Educação pela Universidade Federal da Bahia (UFBA/2013). Professora Adjunta - Nível I da Universidade Federal do Sul da Bahia (UFSB); Docente na Pós-graduação em Agro-Ecologia e Educação do Campo da Universidade Federal do Sul da Bahia (UFSB); Líder do Núcleo de Pesquisa, Ensino e Extensão em Experiência do Sensível (NUPEES) em linhas de Estudos e Pesquisas com Crianças nos seguintes temas: Educação de Infâncias quilombolas e indígenas; Membro do grupo de Pesquisa Imagens e Tecnologias e Infâncias (PPGE/UFES) com o tema de pesquisa: Culturas Infantis em comunidades tradicionais.

\section{Maria Angélica Vago-Soares}

angelica_vago@hotmail.com

Graduada em Educação Artística pela Universidade Federal do Espírito Santo (2004). Mestre e Doutora em Educação na área de Linguagens Verbal e Visual (UFES), orientada pela professora Gerda Margit Schütz-Foerste na (PPGEUFES).Participa dos Grupos de Pesquisa: Imagens, Tecnologias e Infâncias (PPGE-UFES) e do Núcleo de Pesquisa, Ensino e Extensão em Experiência do Sensível (NUPEEES- UFBA). Professora do Ensino Superior, da Universidade Federal do Espírito Santo (UFES), no Centro de Educação - Departamento de Cultura, Linguagens e Educação. Autora do livro: Infância, Arte e Cultura: experiências em (com)textos educativos, 2015 e do Conto infantojuvenil: Quita e Kristal: aventuras em uma cidade, 2020. 